\title{
Promoting Critical Reading with Double-Entry Notes: A Pilot Study
}

\author{
Lindsey Ives, $\mathrm{PhD}$ \\ Assistant Professor, Humanities and Communication Department \\ Embry-Riddle Aeronautical University \\ Taylor Joy Mitchell, PhD \\ Associate Professor, Humanities and Communication Department \\ Embry-Riddle Aeronautical University \\ Helena Hübl, MA \\ Visiting Instructor, Humanities and Communication Department \\ Embry-Riddle Aeronautical University
}

\begin{abstract}
Recognizing a need to promote critical reading among students at our STEM university, the authors implemented an active reading strategy called double-entry notes across four general education writing and humanities courses. We hypothesized that the tool would help engage students in the critical reading strategies they tended to lack. The tool aimed to encourage students to think critically about assigned readings by analyzing texts, applying assigned readings to the world outside the text, synthesizing multiple texts, and the like. After assigning the tool, we assessed its effectiveness through a survey of students' perceptions and coded artifacts $(\mathrm{N}=182)$ for six markers of critical thinking. Results suggest that the tool succeeded in helping students to think critically about texts but that some markers of critical thinking were more consistent than others. Also, students' perceptions of the double-entry notes' benefits did not align with our findings based on analysis of their texts. Because results revealed critical engagement in reading, we plan to continue the study, adjusting the tool to address more specific critical thinking strategies.
\end{abstract}

In Fall 2018, 80\% of undergraduates on Embry-Riddle Aeronautical University's Daytona Beach Campus (ERAU) were enrolled in aviation or engineering programs ("Fall 2018," 2019). This suggests that students predominantly attend ERAU with the ambition to fly airplanes or build rocket ships, rather than read lofty literary texts or write analytical essays. Due to the intense course load of ERAU's STEM programs, students are given limited opportunities to focus primarily on learning or developing critical reading and communication skills. The bulk of this learning occurs in general education courses, most often taken in the first and final years of study. Enrolling in these general courses only at the beginning and end of STEM students' academic careers reinforces the misconception that these courses are not integral to their primary field of study. For instance, in the 2018-19 Aerospace Engineering Flowchart (Figure 1), communication and writing courses are pushed as far away as possible from major courses, unlike the general education math courses listed at the top. Physically representing communication and writing courses so low on the chart and so far removed from other courses incorrectly implies to students that these courses are of lowest priority and tangential to their major and future careers.

InSight: A Journal of Scholarly Teaching 
Figure 1

ERAU's Aerospace Engineering Flow Chart 2018-19 (Aerospace, 2018)

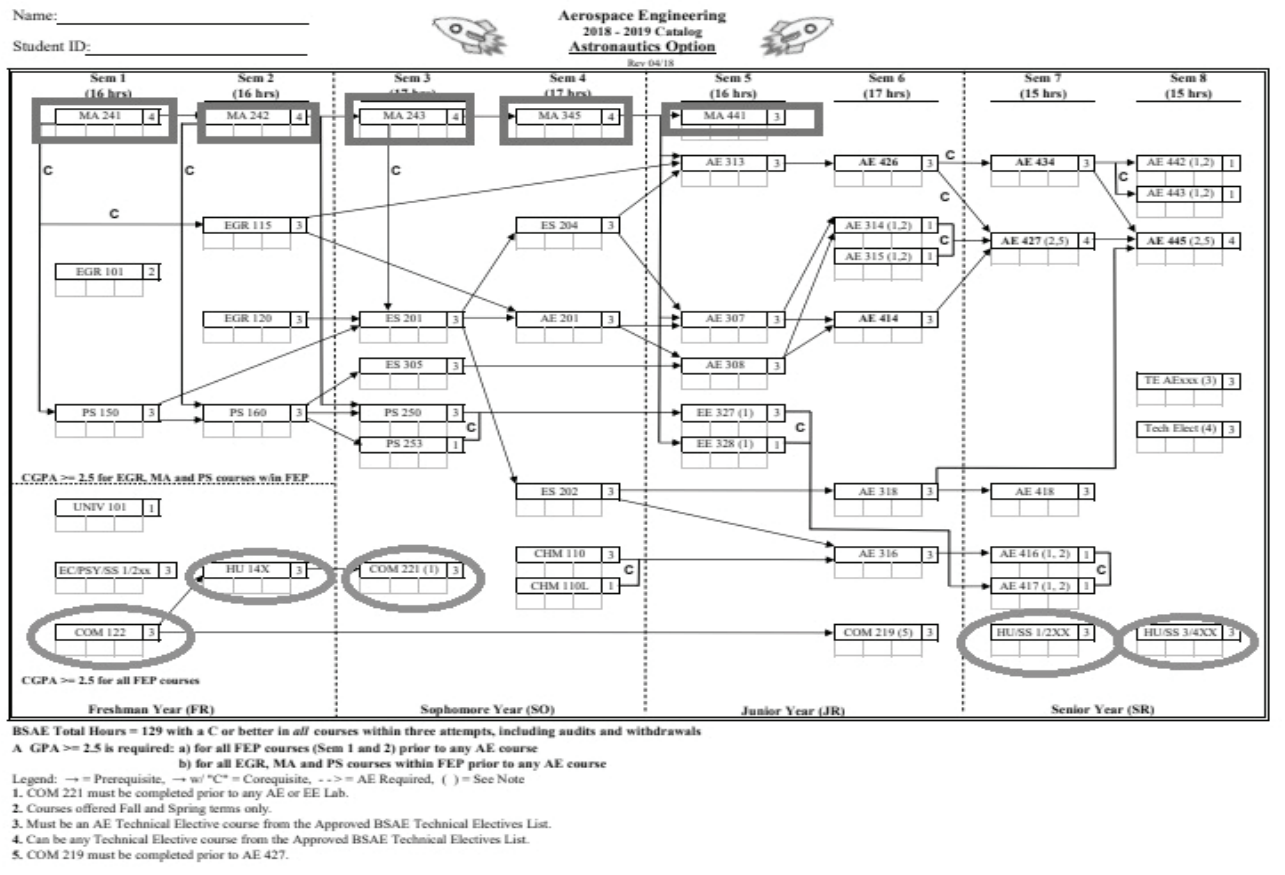

Thus, like other general education instructors at STEM institutions, writing and humanities instructors at ERAU must consistently remind students that critical reading and communication skills are relevant to their degree programs and future careers because they will enhance their critical thinking.

The relevance of these skills was recently illustrated by the results of an ERAU career readiness survey. In 2017, ERAU's Career Services and Division of Student Affairs designed and administered a survey to known employers of ERAU graduates. The Career Readiness Competencies Employer Survey was based on the eight key competencies developed by the National Association of Colleges and Employers (NACE). NACE's Critical Thinking/Problem Solving Competency states that students properly prepared for a career will "Exercise sound reasoning to analyze issues, make decisions, and overcome problems. The individual is able to obtain, interpret, and use knowledge, facts, and data in this process, and may demonstrate originality and inventiveness" ("Career Readiness Defined," 2019). When asked to rank the importance of this competency, 97\% of employers who hire ERAU graduates ranked critical thinking skills as "important" or "very important" ("Career Readiness Competencies," 2017). These results validate the recent emphasis on the critical thinking competency in ERAU's General Education Program.

In the summer of 2017, our General Education program streamlined eleven learning outcomes into seven core competencies and now lists critical thinking above the others. ERAU graduates should be able to "synthesize and apply knowledge in 
order to define and solve problems within professional and personal environments" ("General Education," 2019). Based on the high ranking by known employers and our General Education program, we-as general education instructors-needed to find ways to better promote critical thinking in our writing and research courses.

In order to promote critical thinking about texts in our writing and humanities courses, we assigned double-entry notes (DENs). Double-entry note-taking is a reading/thinking strategy recommended in a number of writing textbooks (Payne, 2017; Ramage et al., 2006). DENs enable students to record their responses to texts as they read. While this assignment has many variations, in its most basic form, a set of DENs consists of two columns. In one column, students indicate what the text says by summarizing, quoting, or paraphrasing passages. In the other column, students respond to the text in some way by analyzing, interpreting, emoting, and the like. A successful response shows that the student has thought about the passage and done something new with it. While DENs have been used in many contexts since the early 1980s (Bean, 2011; Berthoff, 1981; Friedman, 1991), the instrument has not been widely studied in the context of developing student critical thinking and reading, which was our goal. Therefore, we developed a pilot study to assess whether, how, and to what extent the strategy promotes critical thinking among students.

The study was guided by the definition of critical thinking provided by the Council of Writing Program Administrators in the "critical thinking, reading, and composing" outcome of their "WPA Outcomes Statement for First-Year Composition" (2014): "Critical thinking is the ability to analyze, synthesize, interpret, and evaluate ideas, information, situations, and texts." We used this definition because its focus on critical thinking about texts aligns with our own Communication and Humanities course goals and with the goals of the DEN assignment. While only one first-year composition (FYC) course was included in this pilot study, the other courses help students build upon the knowledge gained in FYC by applying that knowledge in increasingly specialized contexts, so the FYC outcomes remain relevant.

\section{DENs, Critical Reading, and Thinking}

Critical reading is a necessary component for critical thinking and a practice that composition scholars argue is crucial for success in academic and civic life (Carillo, 2017; Horning, 2007). Students can think critically about a text only if they have critically read the text; since "thinking cannot be divorced from content," students need to be given the chance to practice thinking and reading skills in and across as many disciplines as possible (Carr, 1988, p. 69). Requiring students to read critically forces them to engage in a cognitive process, one that involves the reader interacting with the text in a specific activity (Ehri, 1995; Sweet \& Snow, 2003). As a non-linear process, critical reading requires "helpful thinking, flexible strategies, and periodic selfmonitoring" (Paris \& Jacobs, 1984, p. 2083). Because critical reading and thinking can be understood as co-dependent, critical reading is important for all students regardless of major.

Despite the importance of critical reading, studies have shown that a majority of college students do not complete assigned readings. A longitudinal study by Burchfield and Sappington (2000) found that reading compliance among college 
students decreased over the course of more than a decade. Studies reviewed by Kerr and Frese (2017) indicate that only 20 to 30\% of undergraduates complete assigned reading and that a variety of factors prevent college students from reading, including “1) unpreparedness, 2) lack of motivation, 3) time constraints, and 4) an underestimation of reading importance" (p. 28). Regardless of what factor prevents students from reading the assigned material, by not reading the material, students are not engaging with the course content or developing the much-sought after critical thinking skills. Coupled with the dwindling reading statistics among college students, researchers have found that faculty across disciplines deliver content through lectures and notes, making assigned reading seem unnecessary (Del Principe \& Ihara, 2016, p. 230). Faculty fail to enforce reading compliance for a variety of reasons, the most prevalent being the fear that doing so will result in negative course evaluations (Lei et al., 2010, p. 221). However, enforcing reading compliance in engaging ways leads to positive responses among students instead of the kinds of negative responses that hurt course evaluations.

Faculty can use a wide range of strategies to encourage students to read, including quizzes, participation points, and assigned summaries (Lei et al., 2010). Reading logs or learning log assignments like DENS, in which students answer questions or otherwise respond to readings for homework, are also commonly used to encourage reading. In a study comparing random quizzes, non-random quizzes, and assigned learning logs, all of which asked students to identify key components of texts and respond to them, Carney et al. (2008) found that while all three methods motivated students to complete assigned readings, the learning log method assigned for homework motivated students significantly more than the random quiz method, and it "increased students'

...faculty across different disciplines assign readings for a wide range of purposes and should provide explicit guidance for students in order to help them read strategically in order to achieve those different purposes.

perception of their abilities to contribute to discussions significantly more than" the random and non-random quiz methods (p. 198). While the learning log method proves useful in preparing students for class discussions, the method of encouragement should reflect the purpose of the assigned reading. As Ihara and Del Principe (2018) argue, faculty across different disciplines assign readings for a wide range of purposes and should provide explicit guidance for students in order to help them read strategically in order to achieve those different purposes.

DENs, which can be viewed as "a slightly more structured version of a reading log" (Bean, 2011, p. 178), have traditionally been used to assist students in literary analysis and improve their reading and writing processes (Bean, 2011; Berthoff, 1981; Evering \& Moorman, 2012; Friedman, 1991). Because DENs can be tailored to serve a wide variety of purposes, we decided to use DENs - rather than quizzes, marginal notation, or reading guides-to improve critical thinking skills. We specifically designed them to be unique to each course's goal. The DENs we designed to engage students in a variety of reading assignments across our four writing and humanities classes. Our hypothesis was that the DENs would assist with critically reading texts in multiple modes, as well as critically thinking about the scholarly texts. 


\section{Cases}

We assigned DENs in four writing and humanities courses (six sections in total) throughout the spring 2018 semester. Even though the goals and requirements for each course are different, they all aim to promote writing and research skills, and each is intended to satisfy ERAU's General Education Critical Thinking competency. Additionally, all courses are requirements for graduating from our institution. Below is a table (Table 1) that summarizes the courses used in our multiple-case study. The courses are listed in order of ERAU's intended writing sequence; for example, the Freshman Composition (COM 122) serves as a prerequisite for the lower-level humanities (HU) course, and the lower-level HU course serves as a prerequisite for the Technical Report course. We describe how and why DENs were used in each course below.

Table 1

Summary of Cases

\begin{tabular}{|c|c|c|c|c|}
\hline Class & Sections & $\begin{array}{c}\text { Sets of DEN } \\
\text { Assigned }\end{array}$ & $\begin{array}{l}\text { Assignment } \\
\text { Purpose }\end{array}$ & $\begin{array}{c}\text { \# of DEN } \\
\text { Samples } \\
\text { Coded }\end{array}$ \\
\hline $\begin{array}{l}\text { COM 122: } \\
\text { Freshman } \\
\text { Composition }\end{array}$ & 1 & 3 & $\begin{array}{l}\text { DEN } 1 \text { \& 2: Prep } \\
\text { for assigned } \\
\text { reading \& } \\
\text { written } \\
\text { response; 3: } \\
\text { Analyze sources } \\
\text { for research } \\
\text { argument }\end{array}$ & 26 \\
\hline $\begin{array}{l}\text { HU 144: } \\
\text { Studies in Art }\end{array}$ & 2 & 1 & $\begin{array}{l}\text { Analyzing } \\
\text { source for final } \\
\text { art appreciation } \\
\text { essay }\end{array}$ & 50 \\
\hline $\begin{array}{l}\text { COM 221: } \\
\text { Technical } \\
\text { Report Writing }\end{array}$ & 2 & 1 & $\begin{array}{l}\text { Analyze sources } \\
\text { for the } \\
\text { analytical report }\end{array}$ & 27 \\
\hline $\begin{array}{l}\text { HU 395: } \\
\text { Contemporary } \\
\text { Texts }\end{array}$ & 1 & 5 & $\begin{array}{l}\text { Analyze } \\
\text { scholarly } \\
\text { sources to better } \\
\text { understand the } \\
\text { primary texts }\end{array}$ & 79 \\
\hline
\end{tabular}

InSight: A Journal of Scholarly Teaching 
ERAU students are required to complete one 100-level writing course, which focuses on research-based academic argumentation. While assigned topics vary, all students must write top-down, thesis-driven academic arguments that put multiple credible sources into conversation and document those sources in MLA style. In the section we analyzed for this study, students produced three sets of DENs. In the first two, students responded to assigned articles in order to prepare for class discussions and for a short argumentative reading response to one of those articles. Later in the semester, they completed a set of DENs (Figure 2) in which they analyzed quotes from multiple sources they located themselves in preparation for their research-based arguments. Prompting questions for the analysis column encouraged students to relate the quote being analyzed to their research questions, personal experiences, and other sources and/or to consider how readers from different backgrounds might see the quote differently. In each case, they were encouraged to use some of the quotes and analysis from the DENs in their arguments.

Figure 2

DEN for COM 122 with Instructions for Analysis

\begin{tabular}{|l|l|l|}
\hline Location & What it says & What I think \\
\hline Works Cited Entry & \multicolumn{2}{|l|}{} \\
\hline & & \\
\hline
\end{tabular}

Questions you might answer in the right column might include but are certainly not limited to the following:

- How does this quote or paraphrase relate to your research question?

- How does this quote or paraphrase relate to your experiences?

- How does the quote or paraphrase relate to other sources that you have read?

- Do you agree or disagree with the quote or paraphrase?

- Does this quote make you think about your topic differently than you did before?

How might someone from a different culture, discipline, or generation see this topic differently than the author quoted here?

\section{HU 144: Studies in Art}

After ERAU students pass COM 122, they can enroll in a lower-level humanities course. Students can choose from many different themes for their required lower-level humanities course, including music, art studies, film, and literature. Regardless of the theme, the course culminates with major writing assignment (MWA) that asks them to analyze a primary artifact while being in conversation with multiple sources. The DEN (Figure 3) we created for this course was assigned to inspire further research for the MWA. Students were asked to analyze two quotes from a scholarly article, but rather than merely explain how they would use the source, they had to ask 
questions that were prompted by the lack of information in the article, or questions that required additional research. By performing this additional step, students were able to immediately evaluate the quality of their sources and determine whether additional sources were needed; therefore, they worked toward the critical thinking aspects of understanding primary/secondary texts, making connections between primary artifacts and historical context, evaluating credibility and challenging or qualifying secondary texts, and relating to a primary or secondary purpose. The DEN assignment was graded, but as a low-stakes percentage of their final grade.

\section{Figure 3}

DEN for Studies in Art with Instructions for Analysis

\begin{tabular}{|c|c|c|}
\hline $\begin{array}{l}\text { Works } \\
\text { Cited } \\
\text { Entry }\end{array}$ & \multicolumn{2}{|c|}{$\begin{array}{l}\text { Martinez, Juan A. "Lorenzo Romero Arciaga." Cuban Art and National Identity, } \\
\text { the Vanguardia Painters, 1927-1959, University Press of Florida, 1994, pp. 92-93. }\end{array}$} \\
\hline Thesis & \multicolumn{2}{|c|}{$\begin{array}{l}\text { Lorenzo Romero Arciaga's The Cup of Coffee is a controversial piece because of } \\
\text { the possibly illegal nature of its provenance, but that only adds to the emotional } \\
\text { reaction viewers, and especially Cuban exiles, feel towards the vibrant and } \\
\text { historically important painting. }\end{array}$} \\
\hline & $\begin{array}{l}\text { Signal phrase, Quote, and In-text } \\
\text { Citation }\end{array}$ & $\begin{array}{l}\text { 1. In which specific section/s will you } \\
\text { use this and how (say something new)? } \\
\text { 2. What other research does this quote } \\
\text { require/inspire? }\end{array}$ \\
\hline 1. & $\begin{array}{l}\text { According to Juan Martinez, from } \\
\text { the University of Florida, } \\
\text { "Lorenzo Romero Arciaga was } \\
\text { born in 1905, in Havana, where he } \\
\text { still resides. He studied painting } \\
\text { and sculpture at the Academy of } \\
\text { San Alejandro in Havana, } \\
\text { abandoning it in the late 1920s for } \\
\text { the informal teachings and } \\
\text { primitivism of Victor Manuel" } \\
\text { (92). }\end{array}$ & $\begin{array}{l}\text { 1. I'll use this quote in my Biography and } \\
\text { Historical Context sections, but I think I } \\
\text { can also use it in the Artist's Influences } \\
\text { section once I find out more about Victor } \\
\text { Manuel. Since he was born in 1905, it's } \\
\text { clear that he doesn't still live in Cuba, but } \\
\text { at the time this book was published } \\
\text { (1994), he did. So, that tells me he never } \\
\text { left Cuba during any of the political } \\
\text { upheaval during Batista's or Castro's } \\
\text { reign. Also, if he left school, that probably } \\
\text { means he wasn't interested in classical } \\
\text { modes of creating art, which is evident in } \\
\text { the unique style of this famous painting. } \\
\text { 2. Why didn't Arciaga ever leave Cuba? } \\
\text { Did he support Batista? What is the San } \\
\text { Alejandro Academy? Is it a famous } \\
\text { university? What is "primitivism"? Who } \\
\text { was Victor Manuel? What influence did } \\
\text { Manuel have on Arciaga and this } \\
\text { particular painting? }\end{array}$ \\
\hline
\end{tabular}


Meant to prepare students to write in their disciplines and in the workplace, Technical Report Writing is the next course in ERAU's writing sequence. While assignments vary, all students who complete this course are required to write an analytical report of at least 2000 words about a technical topic of their choice. They must write their report for a specific person or group, who they should think of as their client. They must analyze information based on analytical criteria that reflect their purpose and the client's needs. Ultimately, the client should be able to take action based on the report's findings. Students in this course completed DENs (Figure 4) in preparation for their analytical reports. Prompting questions encouraged students to analyze sources from their client's perspective and consider how those sources relate to their research question and analytical criteria.

Figure 4

DEN for COM 221 with Instructions for Analysis

\begin{tabular}{|l|l|l|}
\hline Location & What it says & What I think \\
\hline $\begin{array}{l}\text { References Page } \\
\text { Entry }\end{array}$ & \multicolumn{2}{|l|}{} \\
\hline & & \\
\hline
\end{tabular}

Questions you might answer in the right column might include but are certainly not limited to the following:

- How does this quote or paraphrase relate to your research question?

- How does the quote or paraphrase relate to other sources that you have read? Does it back up information from another source? Contradict it? Present a different angle? etc.

- To which evaluation criterion is this quote most relevant and why?

- Does this quote make you think about your topic differently than you did before?

- Why might this quote be of interest to your audience?

\section{HU 395: Contemporary Texts}

One of the final general education courses students must complete is an approved upper-level Humanities course. Students can select from a wide array of courses and content to engage with, but each student must complete significant research and compose an analytical essay. In Contemporary Texts, students critically read seven graphic novels and complete a research essay that incorporates at least five secondary, credible sources. Because most students had not previously encountered literary scholarship, they were required to read five scholarly articles that were paired with the primary texts assigned in class. For these five scholarly articles, students were required to complete a DEN (Figure 5). This scaffolded exercise was intended to help students better analyze the primary text, learn how to read scholarly texts, and find and engage with poignant quotes. The DENs were graded as low-stakes assignments. 
Figure 5

DEN for Contemporary Texts with Instructions for Analysis

HU 395: Double-Entry Notes

Maus I: Chute's "History and the Graphic Representation Maus"

1. Review the abstract, title, and subtitles

2. Read the introduction and conclusion

3. Skim the Works Cited/References page

4. Write a Works Cited entry for the article below (Use MLA $8^{\text {th }}$ edition, OwlPurdue, article in scholarly journal)

5. Determine what you think might be the overall argument/purpose

6. Read the entire article actively

7. Note what sources/evidence the author uses to support the overall argument/purpose

8. Determine if you were persuaded by the argument/purpose

9. Find FIVE quotes from the article that might help you better understand the primary text

10. Complete the table below, using evidence from the primary text and the scholarly article, as well as any connections to other texts/courses/events

\begin{tabular}{|c|c|c|}
\hline $\begin{array}{l}\text { Works Cited Entry for } \\
\text { Article: }\end{array}$ & & \\
\hline $\begin{array}{l}\text { Overall Argument of } \\
\text { Article: }\end{array}$ & & \\
\hline $\begin{array}{l}\text { Quote/Page \# from } \\
\text { Scholarly Text }\end{array}$ & Explanation of Selection & Critical Evaluation \\
\hline $\begin{array}{l}\text { - Copy and paste quote } \\
\text { that stands out to you in } \\
\text { this box. } \\
\text { - Put the page number of } \\
\text { the quote in ( ). } \\
\text { - Find quotes that "speak" } \\
\text { to you for some reason. } \\
\text { Maybe the quote clarifies } \\
\text { something you've been } \\
\text { trying to articulate. } \\
\text { Maye the quote is just an } \\
\text { example of beautiful } \\
\text { language. Maybe the } \\
\text { quote is written in super } \\
\text { confusing academic } \\
\text { language, and you have } \\
\text { no idea what it might } \\
\text { mean. }\end{array}$ & $\begin{array}{l}\text { - Why did you pick this } \\
\text { quote? } \\
\text { - What strikes you about this } \\
\text { quote? } \\
\text { - Is the quote a basic } \\
\text { definition or explanation of } \\
\text { the primary text? } \\
\text { - Is the language } \\
\text { understandable? } \\
\text { - Is this quote a good } \\
\text { example of analysis? } \\
\text { - Is this quote a sweeping } \\
\text { generalization? } \\
\text { - Does this quote need more } \\
\text { support? }\end{array}$ & $\begin{array}{l}\text { - What does this quote } \\
\text { make you think of or } \\
\text { remember? } \\
\text { - How does this quote } \\
\text { help you understand } \\
\text { the primary text better? } \\
\text { - Do you want to } \\
\text { challenge or qualify this } \\
\text { quote? In what ways do } \\
\text { you agree with it? } \\
\text { Disagree? } \\
\text { - What else have you } \\
\text { read/heard/experienced } \\
\text { that connects with this } \\
\text { quote? } \\
\text { - Does something } \\
\text { confuse you or lead to } \\
\text { further questions? } \\
\text { - How does this quote } \\
\text { make you feel about the } \\
\text { primary text? }\end{array}$ \\
\hline
\end{tabular}

InSight: A Journal of Scholarly Teaching 


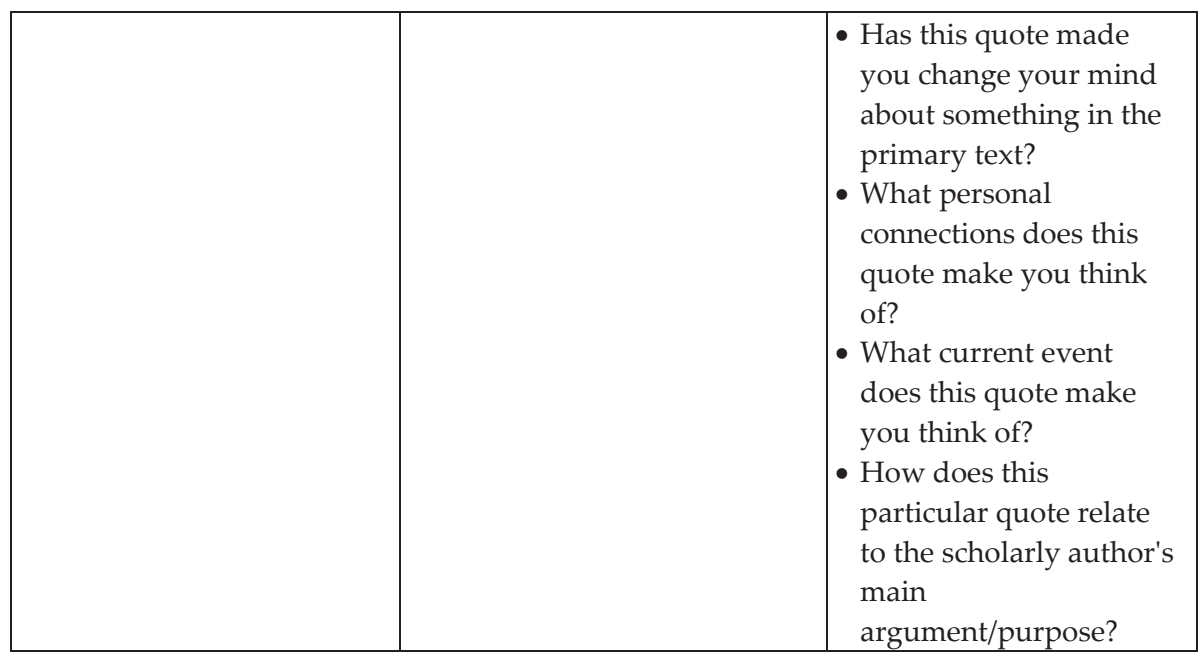

The five DENs were placed in a grading category with multiple online reading guides, and all of the critical reading assignments were weighted at $8 \%$ of a student's final grade. Unlike the other cases in this pilot study, this case did not require students to then apply the work completed in the DENs into a final essay. In some instances, students happened to select a novel or analysis that was discussed in one of the assigned scholarly texts, but more likely, students selected novels not read in class or analyzed topics not mentioned in the assigned scholarly texts. Since this pilot study focuses strictly on analyzing the DENs--not the final essays--this particular difference does not skew data, and because students still had to complete an analytical essay, those artifacts can still be assessed for critical thinking.

While each of our DENs tools are different, they all address basic critical thinking components. For instance, in Contemporary Texts, the DENs require students to not only comprehend the scholarly text's overall argument/purpose and apply selected quotes from the scholarly article to the primary text, the tool also asks students to make connections between a selected quote and historical/cultural context, or other texts/events and situate selected quotes within scholarly conversations previously read. In addition to these outcomes, we hoped using DENs would facilitate critical thinking about primary and secondary sources.

\section{Analytical Approaches}

In order to assess whether DENs assisted in the development of critical thinking skills, we used a methodological approach that analyzed the cases described above as multiple bounded systems (Cresswell, 2013, p. 97) through indirect and direct assessment measures. Funded initially by ERAU's Center for Teaching and Learning, we secured IRB permission to analyze participating students' survey responses and completed DENs.

For our indirect measure, we surveyed 82 students about their perceptions of the effectiveness of this tool at the end of the semester. At the end of spring 2018 after all of the DENs were assigned and graded, but before we coded any, we surveyed 
students regarding their perception of the DENs' effectiveness. Survey statements asked students to rate their level of familiarity with DENs before the course and the extent to which the tool helped them to analyze, evaluate, integrate, and synthesize sources on a five-point Likert scale, with 1 being "not at all" and 5 being "a great deal."

- To what extent were you familiar with DENs before to this course?

- To what extent did double-entry notes help you more carefully analyze (think critically about) texts and/ or images in this course or others?

- To what extent did double-entry notes assist you in evaluating the credibility of a source or the source's overall argument/ purpose?

- To what extent did double-entry notes help you integrate quotes/ sources into a final product such as a paper/ essay?

- To what extent did double-entry notes help you synthesize (combine) information from multiple texts and/ or images into a final product such as a paper/ essay?

We used Google Forms and a tiny url link to distribute the anonymous survey during class time. Students who did not wish to participate in the pilot study did not have to complete the survey. If students were absent, they were sent the link, but because it was anonymous, we could not verify completion.

Our direct measure involved calibration sessions, coding 182 DENs using Nvivo software for markers of critical thinking, and discussion of the coding experience. Nvivo software is a qualitative and mixed-methods data analysis computer software designed for analyzing text-heavy or multimedia information. The software allows researchers to make connections between and find insights on multiple texts through the use of nodes, or what we refer to as codes to analyze the DENs. These codes were developed during calibration sessions and were based on critical thinking theory and pedagogy:

Understanding- Knowing the article/assignment

Demonstrating- Showing rhetorical awareness of audience, purpose, context, etc.

Applying- Applying information to the thesis, research question, personal experience, primary text, or anything outside the text

Analyzing- Doing something new with the source

Evaluating- Assessing the source; refuting, credibility, hunting assumptions Synthesizing- Putting the source into conversation with other sources

Like Bloom's Taxonomy, these codes move from basic comprehension to higher-order thinking skills. Any time students' responses showed understanding of the article or assignment, we coded it as "understanding." When commentary focused on a source's audience, purpose, or context or explained how a source related to students' own audience, purpose, or context, we coded it as "demonstrating." When commentary made connections between a source and students' own experience or their research question, we coded it as "applying." When students did something new with the source or expressed new insights in response to the source, we coded the commentary as "analyzing." Commentary about a source's credibility or value to the student's project was coded as "evaluating." Finally, comments that related the quote being connected in some way to another source were coded as "synthesizing."

InSight: A Journal of Scholarly Teaching 
Table 2

Codes with Student Examples

Code Examples

Understand "This paragraph will be more or less involving how the class overall has helped me gather a greater understanding of the arts, and how I feel I have achieved that this semester."

Demonstrate "This quote hit me hard and seemed to rearrange my entire view of this piece. No longer did I see a somewhat engaged landscape, I saw a delicate representation of Lawson's personal beliefs and feelings."

Apply "This is related to 'cost' criterion in the report. Obviously, the HSR [high-speed rail] fares are significantly lower than the air. "

Analyze "This quote explains why Marji feels insecure about herself when she looks in a mirror before facing people she truly admires...She may feel the need to mature quickly due to the events of the Iranian Revolution."

Evaluating "I picked this quote because this scene in Maus really stands out to me because of its portrayal of metafiction."

Synthesizing "This quote serves to support a similar quote (seen in the last entry) by Plumer. ... It serves to show that we are getting closer and closer to [self-driving cars'] acceptance of use in everyday society."

Once the DENs were coded with the above-specified nodes, we used Nvivo to aggregate the amount of times we assigned a node on the DENs. For the pilot run of this study, we each coded artifacts from our own courses using the same codes. We later compiled our findings and compared students' survey responses to our coded artifacts.

\section{Results}

\section{Indirect Measure: Student Perceptions}

Our indirect measure (Figure 6) showed that students perceived the DENs as "often" or a "great deal" of help when it came to critical reading and critical thinking, particularly analysis. Of the 82 respondents, $72 \%$ of respondents were not familiar with DENs prior to completing them in their current course. The majority of respondents $(79 \%)$ claimed that the DENs helped them analyze sources at least somewhat, with only $8.5 \%$ of respondents stating they were not at all helpful. Most respondents $(79 \%)$ claimed that the tool helped them synthesize information at least somewhat. A slightly smaller majority $(74 \%)$ thought the tool was helpful when determining a source's credibility or overall argument. This positive response suggests that students, in the least, valued this tool to help practice critical reading strategies. 
Figure 6

Students' Perception of DENs' Benefits by Number of Respondents

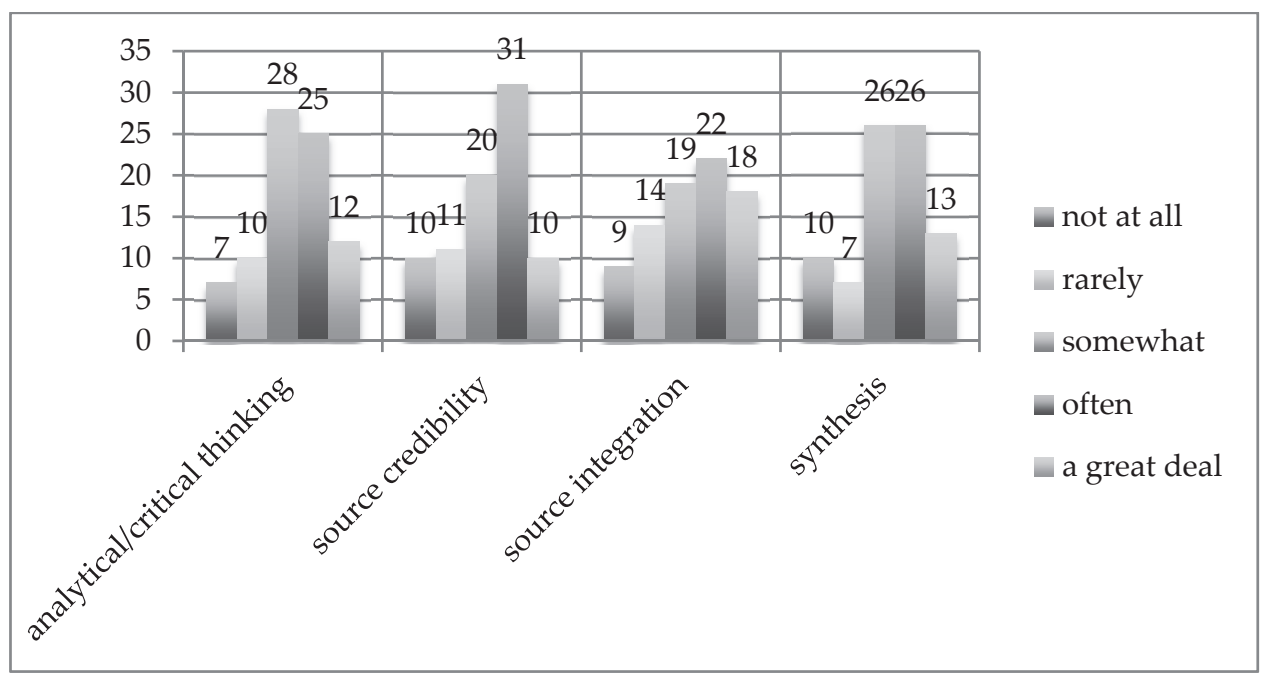

\section{Direct Measure: Coded Artifacts}

Similar to our indirect measure, results from our direct measure reveal that DENs can be useful tools for developing critical thinking skills. Aggregating our codes across artifacts using Nvivo data revealed that students consistently demonstrated the critical thinking moves named in our codes. As Figure 7 shows, the percentage of artifacts that demonstrated each code at least once remained fairly consistent across courses.

Figure 7

Percentage of Samples in which Codes Appeared at Least Once

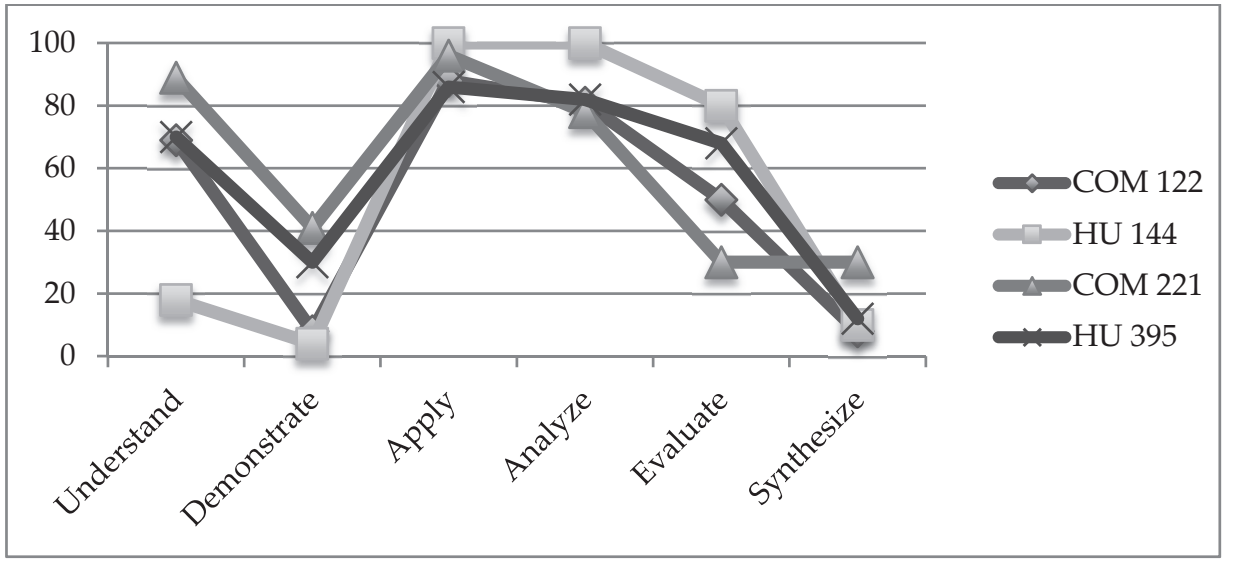

Students from all classes applied and analyzed information at particularly high rates. In Studies in Art, 100\% of students made both moves at least once. In all 
classes, over $80 \%$ of students applied information, and over $75 \%$ of students analyzed information at least once. Not surprisingly, differences in frequency of certain codes reflect the varied purposes for which the DENs were used in each course. For example, a greater percentage of artifacts from Technical Report Writing demonstrated rhetorical awareness at least once than did those from other classes. This reflects the fact that DENs in that course were a step toward the analytical report, for which students had to answer a research question for a specific client. Because the DEN prompt included a question asking how information related to the audience's needs and goals, students in that course demonstrated audience awareness at a higher rate. Similarly, some students assessed the use of certain products in specific situations, which required them to keep purpose and context in mind. Conversely, the fact that only $40 \%$ of artifacts commented on these crucial elements suggests the need for more training on how to address their rhetorical situation when analyzing sources.

\section{Discussion/Conclusion}

This study investigated whether, how, and to what extent DENs encourage students to think critically about texts. As Horning (2007) argues, "'If students can move beyond simple comprehension to analyze, synthesize and evaluate [multimodal texts across disciplines], they will be better readers, writers, students, and citizens of the democratic and electronically connected global society they will join when they graduate" (p. 2). Our findings suggest that DENs do promote the critical reading practices Horning (2007) mentions; however, they are more successful in some areas than others. While the vast majority of students analyzed source material and applied it in some way, only a very small percentage of students demonstrated awareness of sources' audience, purpose, and/or context or synthesized information from multiple texts.

Furthermore, while the high representation of analysis and application suggest that students thought critically about sources while completing the DENs, the high number of "understanding" instances may suggest that students did not think critically about every quote. Although DEN prompts discouraged students from summarizing sources, many artifacts did include summary, and those responses that summarized the quote or reiterated their meaning were coded as "understanding," so that code in some cases points toward a lack of critical thinking. However, in the Contemporary Texts case, the high percentage of DENs coded as "understanding" suggests that assigning multiple DENs throughout the semester helped the students grapple with unfamiliar content and theory. Although not every DENs response showed evidence of critical thinking, the highest scores for applying and analyzing show that each student provided their original thoughts about chosen quotes at least once.

Also striking was the disconnect between students' perceptions of the DENs' value in helping them synthesize sources and the extent to which they actually synthesized sources in the DENs according to our codes. While $79 \%$ of survey respondents said that the DENs helped them to synthesize sources at least somewhat, only $30 \%$ of artifacts from Technical Report Writing and $10 \%$ of artifacts from the three other classes actually synthesized sources in their DENs comments. This may reflect a 
disconnect between the students' understanding of synthesis and our own. It may also suggest that the active reading they did with the DENs helped them to synthesize sources in their final products even if they did not do so in the DENs.

The answer to the how part of our research question provides insight into why students were more successful in some areas than others. Our coding data suggest that guiding questions actually work, showing that faculty can use DENs to provide explicit guidance for purposeful reading, as Ihara and Del Principe (2018) recommend. In our pilot study, the questions guided students to analyze or apply more than synthesize. For example, the Contemporary Texts DEN asks students eight questions they could possibly answer in the critical evaluation column, and four of those guided students to application or analysis (i.e. "What else does this quote make you think of?" or "How does this quote help you understand the primary text better?"). Only one question guides students to synthesis (i.e. "What other scholarly texts does this quote remind you of?"). Our data indicate that students work with texts in the ways that prompts direct them to, so it is not surprising that relatively few responses synthesized sources in this case.

Since our findings show how directive prompt questions can be, faculty in any discipline can develop pertinent, guided questions to ensure that the DENs encourage students to practice discipline-specific critical thinking skills. Indeed, this study points toward the need for future research on DENs' impact on critical reading across disciplines. Our study focused only on the use of DENs for discussions and assignments in writing and humanities courses, but our findings suggest that questions could be adjusted to prepare students to take political science exams, conduct physics experiments, design sociological studies, and so on. In order to use DENs successfully for any purpose, faculty should have clear goals for the assignment and create prompt questions that help students to keep those goals in mind. In addition, the tool can be modified to achieve a range of learning outcomes, and guiding questions can be adjusted from one semester to the next based on strengths and weaknesses of the previous implementation.

While results for this pilot study showed that DENs can be useful tools to develop critical thinking, there were a few limitations to our methodology. First, we were unable to code some artifacts because their format was not compatible with Nvivo. Also, for the pilot run, we did not code each other's artifacts. However, as stated above, we ensured interrater reliability by conducting a norming session using the codes to analyze a sample set of DENs before we began coding. In addition, we did not have a rating scale for the level at which students demonstrated the abilities named in the codes. This limitation made it difficult to measure the extent to which DENs promote critical thinking, which was part of our research question. We will adjust our methodology to overcome these limitations in the next round of our study.

Besides adjusting aspects of our methodology, we will also refine specific aspects of our indirect measure for future studies. Since 144 students were involved in the pilot study, our survey response rate $(57 \%)$ is high enough that we would like to replicate our protocol of using Google Forms and class time to distribute the survey link. We will continue to keep our survey short, as to combat the survey fatigue students feel at the end of the semester. We will also replicate our first statement about prior use of DENs in order to get a baseline for familiarity; we hope this number 
severely decreases each year as students cycle through their general education requirements. To better assess whether DENs promote critical thinking, we will adjust the survey in the following ways:

- Add a drop-down box to allow students to indicate what course they have previously used DENs at ERAU

- More clearly define "synthesize" so that student perceptions are not as drastically different from coding results. The definition for "synthesis" on the student survey didn't match our definition for the synthesis code, so although students thought they were performing that function, assessments of synthesis in the direct and indirect measures did not match.

- Separate evaluating a source's credibility from determining a source, or the source's overall argument/ purpose because the statement seems to conflate two different critical thinking skills.

- Ensure that all structural codes are addressed by a survey statement in order to better compare direct and indirect measures.

Other ways we will improve our study moving forward involve our coding process and procedures:

- Standardize document design: To address discrepancies in the study, we should streamline the DENs' design and ensure each tool has the same amount/type of prompting questions as well as a similar amount of column.

- Standardize Nvivo upload process: To make Nvivo more efficiently aggregate results for our group of researchers, we needed to align our document design and input. We each saved our DENs with slightly differently systems in order to protect student anonymity. We also uploaded our DENs into Nvivo differently. For instance, one researcher uploaded all DENs as one file into Nvivo, while others uploaded individual documents; this made aggregating data by student or DEN impossible. We also uploaded document versions that Nvivo could not properly display.

- Add specific rating levels to codes: Include Likert-scale levels to distinguish how well students are accomplishing critical thinking skills. For example, although $100 \%$ of the Studies in Art students were able to analyze, that code was applied even if they were analyzing on a surface level at least once. By adding a rating scale for complexity (extremely, very, moderately, slightly, not at all) and frequency (almost, always, often, sometimes, seldom, never) we will be able to differentiate between complex and lower level analysis resulting in more accurate measures of that code.

Coupled with coding process issues, we also realized that our study needs to better incorporate DENs into the classroom in a variety of ways:

- Address terminology. The study should reinforce the difference between summarizing and analyzing. In preparing for this pilot study, we theorized that students would be summarizing when they were supposed to be analyzing, but the results didn't prove that outcome. However, the findings did show that although students do know how to analyze, it's only 
superficially, so we should adjust our expectations for the amount and depth of analysis and application the participants are capable of.

- Incorporate the tool through scaffolding, grading, and modeling. Rather than assigning the accompanying readings and DENs as homework, allow time in the classroom for collaboration and peer review and attribute an appropriate amount of time for each assignment.

Our pilot study's success has encouraged us to continue to use DENs in these and other courses to promote critical thinking. We are using our preliminary results to convince other ERAU General Education professors to use DENs, so that students begin to see them throughout their academic course load and begin to recognize how these critical thinking skills will be useful for their future careers. DENs can easily be incorporated into any course that includes a review of or use of scholarship, regardless of field. According to an unsolicited student perception on using DENs in the classroom to develop critical thinking skills, the DENs might be "overall an unenjoyable assignment," but they can teach students how to "analyze other people's texts" and "interpret what" a "specific author is trying to convey to their audience." Overall, this student response (Figure 8) aligns with our findings: the DENs can help the students "analyze other's works to help [them] think critically about the same subject."

\section{Figure 8}

Unsolicited Student Perception of DENs

Question 22

$3 / 3$ pts

You will be missed. Think about your future self. Answer the following question for three points:

In five years from now, what is one specific activity, lesson, or discussion that you might remember about our class?

Your Answer:

While the DEN's were hard to do, required a lot of time, and severe overall an unenjoyable assignment hey taught me Chow to analyze other people's texp an how to interpret whaphat specific author is trying to convey to their audience, not onily awout the specific novel, but the inter-workings of it as well in my career field $\mathrm{t}$ is important to

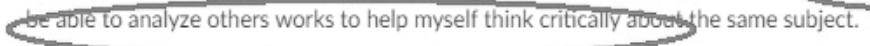

Overall, this study shows that DENs help students to think critically about texts. DENs are an adaptable active reading strategy that should be used to encourage critical reading in a variety of contexts and investigated in future studies. 


\section{References}

Aerospace engineering 2018-2019 catalog: Astronautics option [PDF file]. (2018). Embry-Riddle Aeronautical University. https://erau.edu/-/media/files/daytonabeach/degrees/ae-flowchartsastro.pdf?la=en\&hash=1847A7FD8C4 6BE23C7A71C5E7F8AA6EA64A52F7B

Bean, J. C. (2011). Engaging ideas: The professor's guide to integrating writing, critical thinking, and active learning in the classroom ( $2^{\text {nd }}$ ed.). Jossey-Bass.

Berthoff, A. (1981). The making of meaning: Metaphors, models, and maxims for writing teachers. Boynton.

Burchfield, C., \& Sappington, J. (2000). Compliance with required reading assignments. Teaching of Psychology, 27(1), 58-60.

Career readiness competencies employer survey: Tables report-Fall 2017. (2017). Qualtrics.com.

https://erauir.co1.qualtrics.com/results/p ublic/ZXJhdWlyLVVSXzg2T3ZXVmVjW Fk2azazdP01YTM3ZTg0ZDI4NmRIYzB1 MDBiNzFjMDM=\#/pages/Page_a963986a -e78b-4ad4-a5e0-bf5d21cf7f23

Career readiness defined. (2019). National Association of Colleges and Employers. https://www.naceweb.org/careerreadiness/competencies/careerreadiness-defined/

Carillo, E. (2017). Reading and writing are not connected. In C. E. Ball \& D. M. Loewe (Eds.), Bad ideas about writing (pp. 38-43). West Virginia University Libraries.
Carney, A. G., Fry, S. W., Gabriele, R. V., \& Ballard, M. (2008). Reeling in the big fish: Changing pedagogy to encourage the completion of reading assignments. College Teaching, 56(4), 195-200. https://doi.org/10.3200/CTCH.56.4.195200

Carr, K. S. (1988). How can we teach critical thinking? Childhood Education, 65(2), 69-73.

https://doi.org/10.1080/00094056.1988.105 22400

Cresswell, J. W. (2013) Qualitative inquiry $\mathcal{E}$ research design: Choosing among five approaches. Sage.

Del Principe, A., \& Ihara, R. (2016). "I bought the book and I didn't need it": What reading looks like at an urban community college. Teaching English in the Two Year College, 43(3), 229-244.

Ehri, L. C. (1995). Phases of development in learning to read by sight. Journal of Research in Reading, 18, 116-125.

Evering, L. C., \& Moorman, G. (2012). Rethinking plagiarism in the digital age. Journal of Adolescent $\mathcal{E}$ Adult Literacy, 56(1), 35-44.

https://doi.org/10.1002/JAAL.00100

Fall 2018 residential campus undergraduate enrollment. (2019). Embry-Riddle Aeronautical University. http://news.erau.edu/mediaresources/facts-and-figures/enrollment

Friedman, A. R. (1991). The double-entry journal: Insights into the comprehension strategies of community college developmental readers (Doctoral dissertation). Retrieved from ProQuest. (9136384). 
General education. (2019). Embry-Riddle

Aeronautical University.

https://erau.edu/leadership/accreditation /general-education/

Horning, A. S. (2007). Reading across the curriculum as the key to student success. Across the Disciplines, 4.

https://wac.colostate.edu/docs/atd/article s/horning2007.pdf

Ihara, R., \& Del Principe, A. (2018). What we mean when we talk about reading: Rethinking the purposes and contexts of college reading. Across the Disciplines, 15(2), 1-14.

https://wac.colostate.edu/docs/atd/article s/ihara-delprincipe2018.pdf

Kerr, M. M., \& Frese, K. M. (2017). Reading to learn or learning to read? Engaging college students in course readings. College Teaching, 65(1), 28-31. https://doi.org/10.1080/87567555.2016.122 2577

Lei, S. A., Bartlett, K. A., Gorney, S. E., \& Herschbach, T. R. (2010). Resistance to reading compliance among college students: Instructors' perspectives. College Student Journal, 44(2), 219-229.
Paris, S., \& Jacobs, J. (1984). The benefits of informed instruction for children's reading awareness and comprehension skills. Child Development, 55, 2083-2093.

Payne, M. (2017). Instructor's manual to accompany the curious writer $\left(5^{\text {th }}\right.$ ed.). Pearson.

Ramage, J. D., Bean, J. C., \& Johnson, J. (2006). The Allyn \& Bacon guide to writing ( $4^{\text {th }}$ ed.). Pearson.

Sweet, A. P., \& Snow, C. E. (Eds.). (2003). Rethinking reading comprehension. Guilford Press.

WPA outcomes statement for first-year composition (3.0), approved July 17, 2014. (2014). Council of Writing Program Administrators.

http://wpacouncil.org/positions/outcome s.html. 
Lindsey Ives is an Assistant Professor and Associate Chair of the Humanities and Communication Department at Embry-Riddle Aeronautical University, where she teaches writing courses at all levels. Her research focuses on second-language writing, writing in the disciplines, graduate communication support, and the relationship between language and privilege in a variety of contexts. Her work has appeared in journals such as Across the Disciplines, Rhetoric Review, and TESOL Quarterly and in the collection WAC and Second Language Writers: Research Towards Linguistically and Culturally Inclusive Programs and Practices.

Associate Professor of Humanities and Communication at Embry-Riddle Aeronautical University, Taylor Joy Mitchell teaches first-year composition, literature courses, and honors seminars on American Cold War culture and education. Her research reflects both her interests in cultural studies and composition pedagogy. Her scholarship of teaching and learning includes the co-authored manuscript Agency in the Age of Peer Production for NCTE's Studies in Writing and Rhetoric series, and her study on peer review in the composition classroom was published in CEA Forum.

Visiting Professor of Humanities and Communication at Embry-Riddle Aeronautical University, Helena Hübl teaches first-year composition, speech, and art studies. Her research reflects both her interests in language studies and composition pedagogy. She will continue her scholarship in language studies when she relocates to the Czech Republic this year to teach at Palacky University in Olomouc.

"The very acts of trying to teach well, of adopting a critically reflective practice to improve our teaching and our students' learning, are radical, in that word's literal sense: they are endeavors aimed at fundamental, root-level transformation."

Kevin M. Gannon (2020). Radical Hope: A Teaching Manifesto 